\title{
CHROMOSOMAL POLYMORPHISM IN NUCELLA LAPILLUS
}

\author{
C. R. BANTOCK and W. C. COCKAYNE \\ Department of Biology and Geology, The Polytechnic of North London, \\ Holloway Road, London N7 8DB
}

Received 1.ix.74

\section{SUMMARY}

A technique for the examination of chromosomes in testicular material in Nucella lapillus is described. The diploid chromosome number varies between 26 and 36. Eight pairs of metacentric chromosomes are always present and range in size from $9 \mu$ to $4 \mu$. Additionally, 10 pairs of acrocentric chromosomes $(4 \mu$ to $1 \mu)$ are present in the $2 n=36$ form and correspond to five pairs of metacentric chromosomes in the $2 n=26$ form. Trivalents occur in individuals heterozygous for chromosome arrangements; this is consistent with the interpretation that the polymorphism is Robertsonian in nature.

The southern British distribution of the chromosome polymorphism in Nucella is described. The polymorphism occurs regularly only in bays in the south-west; elsewhere the populations are monomorphic $2 n=26$. Two areas where the polymorphism occurs have been examined in detail. In each of these the frequency of acrocentrics is negatively associated with increasing wave force, but there is some variation suggesting that other factors relating to water movement (tidal currents and range) are important also. It is pointed out that the overall distribution of the polymorphism can be explained on the assumption that a high chromosome frequency is favoured where total water movement is least.

\section{INTRODUCTION}

ROBERTSONIAN chromosome polymorphism occurs in a number of organisms and comparative studies have sometimes revealed spatial patterns from which it is possible to infer evolutionary relationships between races (e.g. Patton, 1969) or adaptive differences between populations (e.g. Staiger, $1954,1957)$. Robertsonian polymorphism in the dog-whelk Nucella lapillus (L.) was reported first by Staiger (loc. cit.), whose findings may be summarised as follows:

(i) The diploid chromosome number varies between 26 and 36 .

(ii) Eight pairs of metacentric chromosomes are always present and do not contribute to the polymorphism.

(iii) Additionally five pairs of metacentric chromosomes are present in the $2 n=26$ form and 10 pairs of acrocentrics in the $2 n=36$ form.

(iv) The relationship between these forms is such that each metacentric of the 10 contributing to the polymorphism corresponds to two non-homologous acrocentrics in the $2 n=36$ form so that trivalents are formed during meiosis in those individuals which derive a metacentric chromosome from one parent and the relevant two acrocentrics from the other. Since there are three possible chromosomal genotypes (two metacentrics, or one metacentric and two acrocentrics, or four acrocentrics corresponding to each of the five pairs of metacentrics, ) there are $3^{5}(=243)$ possible arrangements. 
(v) Monomorphic $2 n=36$ populations were confined to sites sheltered from heavy wave action, but were not found invariably on such shores.

(vi) Monomorphic $2 n=26$ populations were found in exposed sites, but sometimes on sheltered shores also.

(vii) In localities where the $2 n=36$ form occurred at all, populations with intermediate chromosome numbers occupied shores intermediate in exposure.

Staiger's observations were based on a study of 41 populations in an area of approximately 110 sq. $\mathrm{km}$ in the Roscoff region of Brittany, and of seven populations in other parts of northern France. Hoxmark (1970, 1971) confirmed Staiger's findings at Roscoff and examined additionally four populations from Norway, all of which were monomorphic $2 n=26$ irrespective of differences in exposure. Mayr (1963) reports that only the $2 n=26$ form exists on the eastern seaboard of the U.S.A., but gives neither data nor an interpretation. No data have hitherto been available for Britain. Staiger concluded that the polymorphism was adaptive, but Hoxmark considered that factors other than the degree of wave action determined the distribution of the chromosome forms.

The cytological methods used by Staiger involved simple aceto-orcein squashes of the contents of freshly deposited egg capsules. The disadvantages of this method are that (i) over much of the British range of Nucella egg capsules are not produced throughout the year, (ii) since the chromosomes are seen only in meiosis, their detailed morphology is not apparent, and (iii) it is doubtful if such techniques lend themselves to the wide range of pre- and post-fixation treatments now available (e.g. Hsu, 1973) for the elucidation of chromosome structure.

The purposes of this paper are to (i) describe a technique using testicular material which yields mitotic or meiotic chromosomes throughout most of the year, (ii) describe the chromosome complement of Nucella in more detail than was given by Staiger, and (iii) describe the distribution of the polymorphism in Southern Britain.

\section{Methods}

\section{(i) Cytological methods}

The animal is removed from the shell by cutting round the top of the body whorl with bone forceps, starting at the aperture. Males can be recognised by the penis which lies on the right of the head, but since the animal is usually retracted it is necessary to remove at least some of the shell in order to distinguish the sexes. Separation of the columellar muscle from the columella allows the animal to be slipped out of the upper whorl of the shell.

The testis lies above the digestive gland in the visceral hump. It varies in colour from white through orange to deep-brown. Experience showed that orange gonads yield the most divisions and deep-brown gonads the least. The testis is removed from the visceral hump (it does not matter if parts of the digestive gland remain attached to it) and transferred for 30 min to 0.04 per cent colchicine in 50 per cent seawater, where it is broken into pieces about $2-3 \mathrm{~mm}$ across, using fine forceps.

The pieces are transferred to 25 per cent seawater for $30 \mathrm{~min}$. The 
swelling induced by these hypotonic treatments causes any digestive gland cells to become separated from each other and from the testis so that the latter can be almost entirely freed of adherent tissue by gentle flushing with a pipette.

Fixation is carried out in absolute ethanol/glacial acetic acid/chloroform $(45 / 15 / 1)$. Each piece is taken rapidly through four changes of fixative and then broken into smaller pieces. The total time in fixative is not less than 1 hour.

Heat-dried films are prepared by a modification of the method described by Meredith (1969). While still in fixative, the pieces are broken with needles into a coarse suspension. This is transferred to $2 \mathrm{ml}$ centrifuge tubes and spun for a few seconds. The supernatant is removed and 50 per cent acetic acid added. The tube is then shaken vigorously and spun at high speed to throw down larger pieces of tissue; the remainder breaks up into a fine suspension.

Drops of the suspension are placed on $75 \mathrm{~cm} \times 4 \mathrm{~cm}$ slides on a warming plate at $50^{\circ} \mathrm{C}$. Each drop is sucked back into the pipette and the fluid returned to another part of the slide. The cells migrate to the edge of each drop and as the fluid is withdrawn they are heat-dried on to the slide.

The slides are stained in 2 per cent Giemsa in phosphate buffer, $p \mathrm{H}$ 6.5 for $20 \mathrm{~min}$, washed in tapwater, air-dried and mounted in michrome. Alternatively, slides can be stained with 5 per cent lactopropionic orcein for $30 \mathrm{~min}$, washed in 45 per cent acetic acid, taken through cellosolve to michrome essence and mounted in michrome.

Comments. The procedure is theoretically wasteful since females cannot be used. However, almost all the samples that have been taken contain an excess of males (in some cases only this sex was found) so that in practice very little material is wasted. A single testis can yield enough material to make up to 10 slides, though up to four is more usual. A syringe with a blunt 19-gauge needle can be used to produce a fine suspension from fixed material, but this modification sometimes causes cell breakage. Air-dried (as opposed to heat-dried) films can be prepared by the method described for Cepaea nemoralis by Bantock (1972), but the present material usually contains a good deal of sperm which sometimes obscures dividing cells in air-dried films. Material can be stored in fixative at $4^{\circ} \mathrm{C}$ for 12 months without apparent deterioration. The technique works well for other marine gastropods, e.g. Littorina spp. (Dr P. H. Harvey, pers. comm.). Dr Harvey informs us that small littorinids are best extracted from their shells by crushing the latter with a hammer.

\section{(ii) Sampling methods}

One of the difficulties in the study of genetic differences between populations is that while a detailed survey of a particular region may reveal patterns from which it is possible to infer adaptive relationships, it will miss possibly relevant large-scale differences between areas. Conversely, a large-scale survey on its own will fail to detect local variations which may be relevant to an interpretative argument of the whole. In view of these difficulties we decided to combine a large-scale survey with detailed studies of areas which seemed of particular interest. 
Comparative studies of variation in chromosome (or gene) frequencies require that samples should be reasonably panmictic. The size of the panmictic unit in Nucella is unknown but $\mathrm{Mr}$ J. H. Grothers informs us that individuals sometimes remain on the same rock (within a few metres) for over a year, an observation which suggests that mobility is low. Accordingly, sampling was restricted to areas not greater than $10 \mathrm{~m}$ in any one direction though it was sometimes necessary to collect over a larger area (up to $50 \mathrm{~m}$ linear) due to local scarcity. In these cases care was taken not to lump individuals from parts of a shore with obviously different degrees of exposure.

Between 30 and 100 individuals were collected at each site; half-grown individuals were not taken. It has not been possible for us to visit all the collecting sites; local assistance with different parts of the large-scale survey has been given by different people. All the collections for the detailed surveys were made by one of us (C. R. B.). Eighty-nine samples have been taken; in most cases cytological examination was made within a few days of collection. (It has been found that animals sent by post survive best if they are merely wrapped in cloth dampened with seawater.) All the samples were taken between October 1971 and September 1973.

\section{(iii) Estimation of exposure}

Lewis (1964) considers that, broadly speaking, the intensity of wave action on a particular shore depends on its aspect in relation to the prevailing winds, its slope, and its fetch (the distance into the prevailing wind to the nearest land). A consideration of these factors could be of assistance in a comparison between different tracts of shoreline but is inapplicable on a small scale since local variations in topography are at least as important as overall conditions in determining wave intensity. In order to short-circuit the difficulties attendant upon estimating exposure from physical factors, Ballantine (1961) devised a biological scale based on the relative abundance and distribution of selected littoral species, in particular of algae, barnacles and gastropods. Ballantine emphasised that the scale might not apply outside the area in which it was devised (Pembrokeshire) due to factors other than exposure which could affect abundance. It became clear early on in the present study that (i) chromosome number did not vary in a simple way with exposure in most of southern Britain, and (ii) Ballantine's exposure scale was inapplicable over most of the area. In view of these observations, and since some of the collecting was carried out by people with little experience of marine ecology, for the large-scale survey shores were categorised as exposed, intermediate, or sheltered on a completely subjective basis. The procedures adopted for the detailed surveys are described below.

\section{(iv) Analysis}

In most cases the chromosome number was estimated from at least five cells per animal. On the infrequent occasions when chromosome number varied within an individual (see below), the modal number was chosen to represent that animal. In order to compare samples the frequency of acrocentric chromosomes has been calculated for each individual as a percentage 
of what it was potentially capable of possessing. Thus when $2 n=26$ this value is zero, and when $2 n=36$ the frequency is 100 per cent. Intermediate numbers take values of $5,10,15$ per cent, etc. For each sample the mean percentage acrocentrics has been calculated. This procedure thus ignores the universal presence of the eight pairs of metacentric chromosomes which do not contribute to the polymorphism. All of the 89 samples yielded individuals in which chromosome number could be counted but the number of these individuals is much lower than the original sample size. Only samples where four or more individuals could be scored have been used; this leaves 84 samples with a mean size of 10 ; only 16 of the samples contain less than seven individuals. The raw data are available from one of us (C. R. B.).

\section{Results}

\section{(i) Cytological findings}

\section{(a) Frequency of divisions}

Although a systematic analysis of the annual cycle of mitotic and meiotic activity in the testis has not been carried out, three points are worth making. Firstly, cells in mitosis occur regularly between March and the late summer in most material, but are seen rarely during the winter months. The frequency of mitotic cells is usually low but occasionally up to 10 are found on a single slide. Secondly, cells in diakinesis (more rarely in diplotene) can be found from early summer up to January, and are at particularly high frequencies between July and November. Sometimes over 100 diakinetic cells can be found on one slide. It is not usual to find both mitotic and meiotic cells in the same testis. Finally, there is a slight indication that animals in south-west Britain come into season earlier than those in populations further east.

\section{(b) The chromosome complement}

Karyotypes of spermatogonial mitotic metaphases are shown in plates I and II. For descriptive purposes the chromosome complement has been divided into two groups-group A consisting of those chromosomes which are always present and group B consisting of those contributing to the polymorphism.

Group A chromosomes. The eight pairs of metacentric chromosomes in this group can be subdivided into three sub-groups (plates I and II). Subgroup 1 consists of two pairs of large metacentric chromosomes approximately $9 \mu$ long. Sub-group 2 consists of three pairs of submetacentrics (approximately $5 \mu$ ) and sub-group 3 of three pairs of submetacentrics (approximately $4 \mu$ ).

It is usually not possible to distinguish the chromosomes within subgroups, but sometimes spontaneously occurring secondary constrictions are present (arrowed in plate II, 1) which assist in the recognition of homologous pairs.

Group $B$ chromosomes. In the $2 n=36$ form (plate I, l) the 10 pairs of chromosomes forming this group are either telo- or acrocentric, and range in size from $4 \mu$ to less than $1 \mu$. In the $2 n=26$ form (plate I, 2) there 
are five pairs of metacentrics, the largest of which are approximately the same size as the largest Group A chromosomes.

Individuals with intermediate numbers are shown in plate II. The B group consists of a variable number of chromosomes the exact homology of which is not always clear. As there are several ways in which a given intermediate number can be reached, unless the number of trivalents is known it is not always possible to be certain that the karotypes are accurate. For example, plate II, 1 and plate III, 6 show cells from the same animal; the latter possesses four trivalents (arrowed). This implies that the animal is heterozygous for four of the five possible heterozygous arrangements in the $\mathbf{B}$ group, and the chromosomes in plate II, 1 have been arranged accordingly.

Plate II, 2 shows a cell with 34 chromosomes. A comparison with the meiotic configuration was not possible in this animal so that it is impossible to know whether trivalents would have been formed. However, two of the chromosomes (arrowed) are so different from each other and from any of the others that the only way to accommodate them in the karyotype is to assume that they each correspond to two unequal sized chromosomes in the B group. This difficulty is not an artifact of cell breakage and subsequent loss of some of the chromosomes since all the available mitotic figures from this animal were the same.

A cell with 28 chromosomes is shown in plate II, 3. The interpretation implied by the karyotype is probably correct since diplotene cells from this animal (plate III, 4) showed 11 bivalents and two trivalents.

Meiotic cells are shown in plate III. Plate III, 1 and 2 show diplotene and diakinetic cells respectively in the $2 n-26$ form. Each cell has 13 bivalents. Chiasmata can be seen in the former; interstitial chiasmata occur on three of the four larger bivalents. In diakinetic cells the bivalents are so contracted that it is usually impossible to ascertain the distribution and frequency of chiasmata. Plate III, 3-6 shows diplotene and early diakinetic cells from individuals heterozygous for two or more arrangements so that trivalents (arrowed) are apparent. Chiasmata occur only in terminal regions in the trivalents.

A curious feature which has so far eluded explanation is that occasionally there are small differences in chromosome number between cells within the same individual. For example, in one individual 25 cells possessed 26 chromosomes but one cell contained 28. Cell breakage could explain occasional lower numbers but does not easily account for an increased number. Intra-individual change in chromosome number is known to be a systematic and necessary part of development in some animals, e.g. in Cecidomyid Diptera presumptive somatic nuclei lose chromosomes during embryonic divisions (Bantock, 1970), but there is no sign in the present material that numerical variation within a single individual is more than an infrequent and apparently random event. The testis of Nucella usually contains a large number of polyploid cells (frequently undergoing meiosis) which may be nutritive in function, and it is possible that cells with irregular numbers do not develop into functional gametes. Hoxmark (1970) reports a similar numerical variation in Nucella and considers it to be (at least in part) an artifact of the squash technique used in making the preparations. Dr P. Harvey informs us that he has observed numerical variation within individuals of Littorina spp.; it is possible that this may be of rather wide- 


\section{Plate I}

Spermatogonial mitotic metaphases:

1. $2 n=36$. Air-dried film, lacto-propionic orcein.

2. $2 n=26$. Heat-dried film, Giemsa.

The A group consists of eight pairs of metacentric chromosomes ranging in size from $9 \mu$ in sub-group 1 to $4 \mu$ in sub-group 3. 


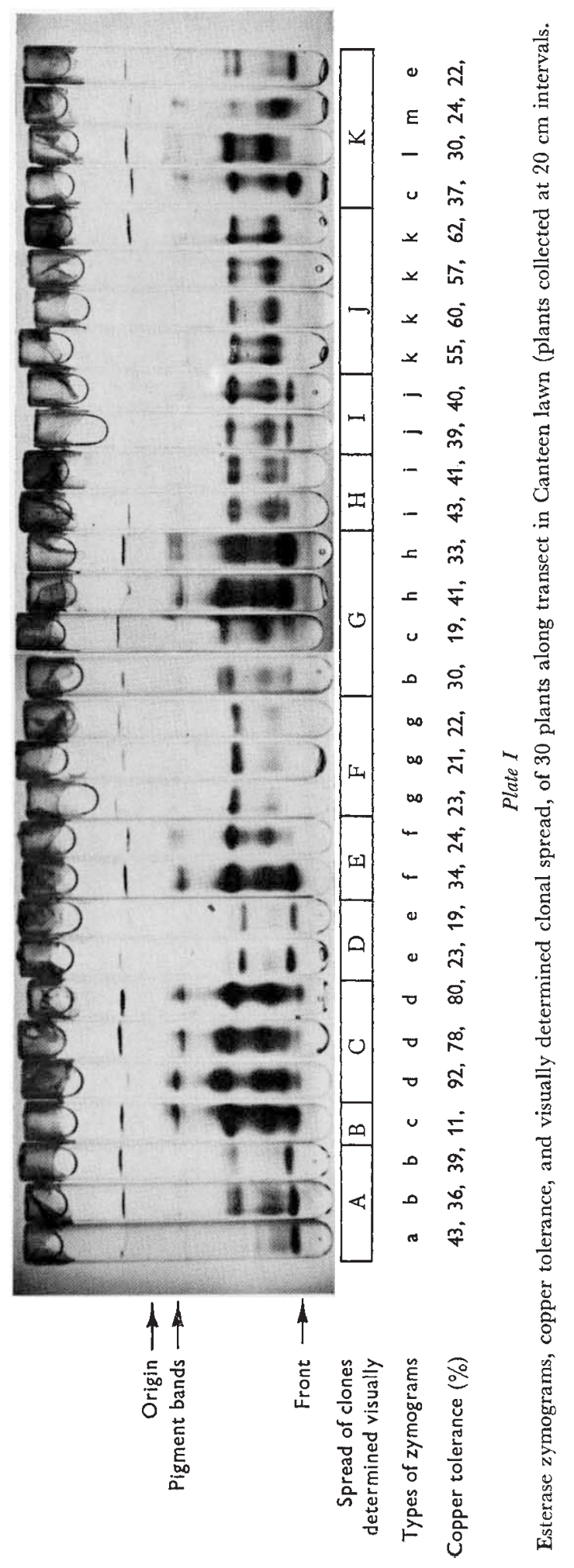




\section{Plate II}

Spermatogonial mitotic metaphases from animals with intermediate chromosome numbers. Heat-dried films, Giemsa.

1. 32 chromosomes. Meiosis in this animal (plate III, 6) showed that four trivalents were present indicating that it was heterozygous for four chromosome arrangements. Secondary constrictions (arrowed) are present in four of the chromosomes of the A group.

2. 34 chromosomes. Two of the metacentric chromosomes (arrowed) are so different from each other and from any of the others that it is likely that they each correspond to two acrocentric chromosomes in the B group.

3. 28 chromosomes. Meiosis in this animal (plate III, 4) showed that two trivalents were present indicating that it was heterozygous for two of the chromosome arrangements. 


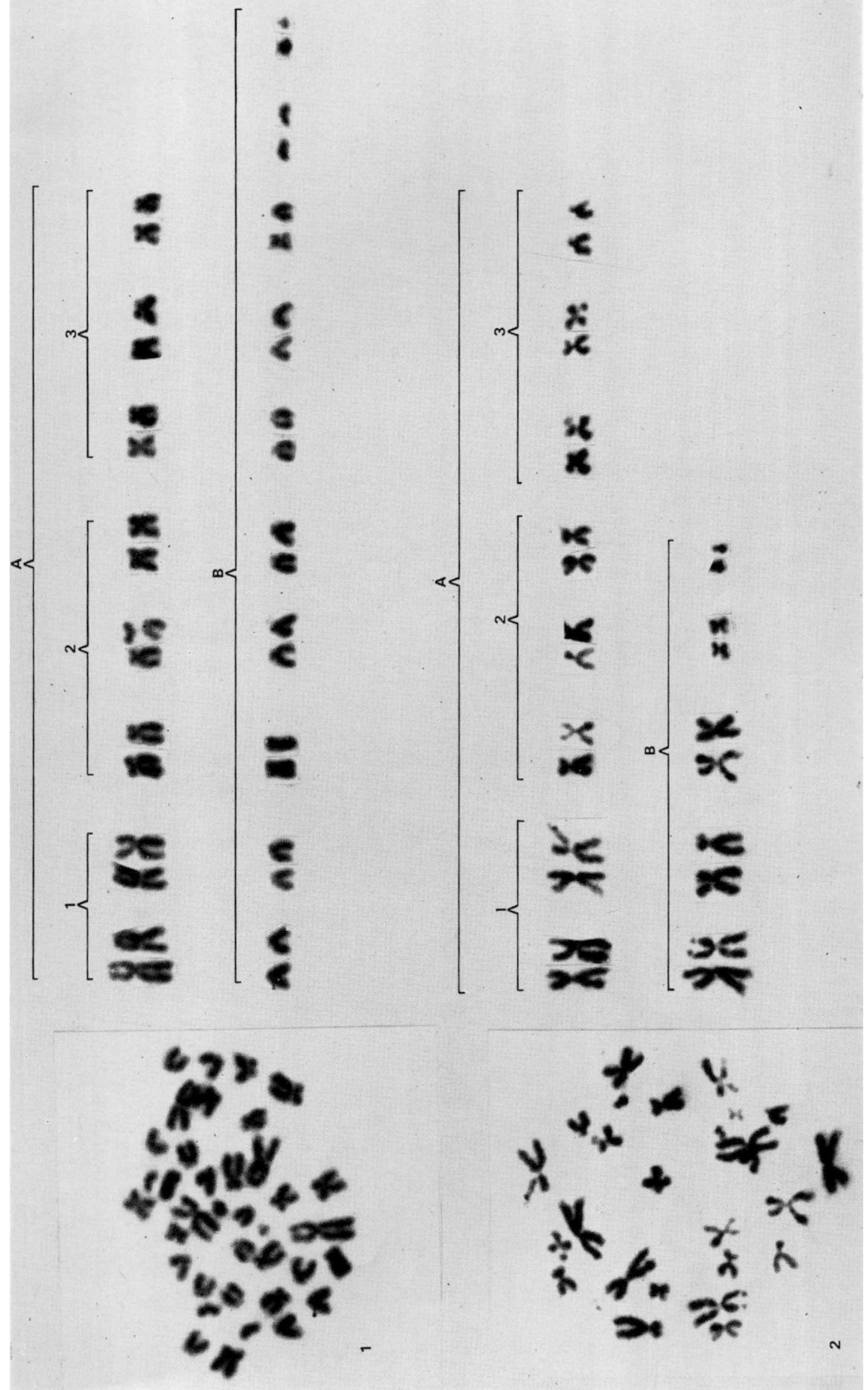




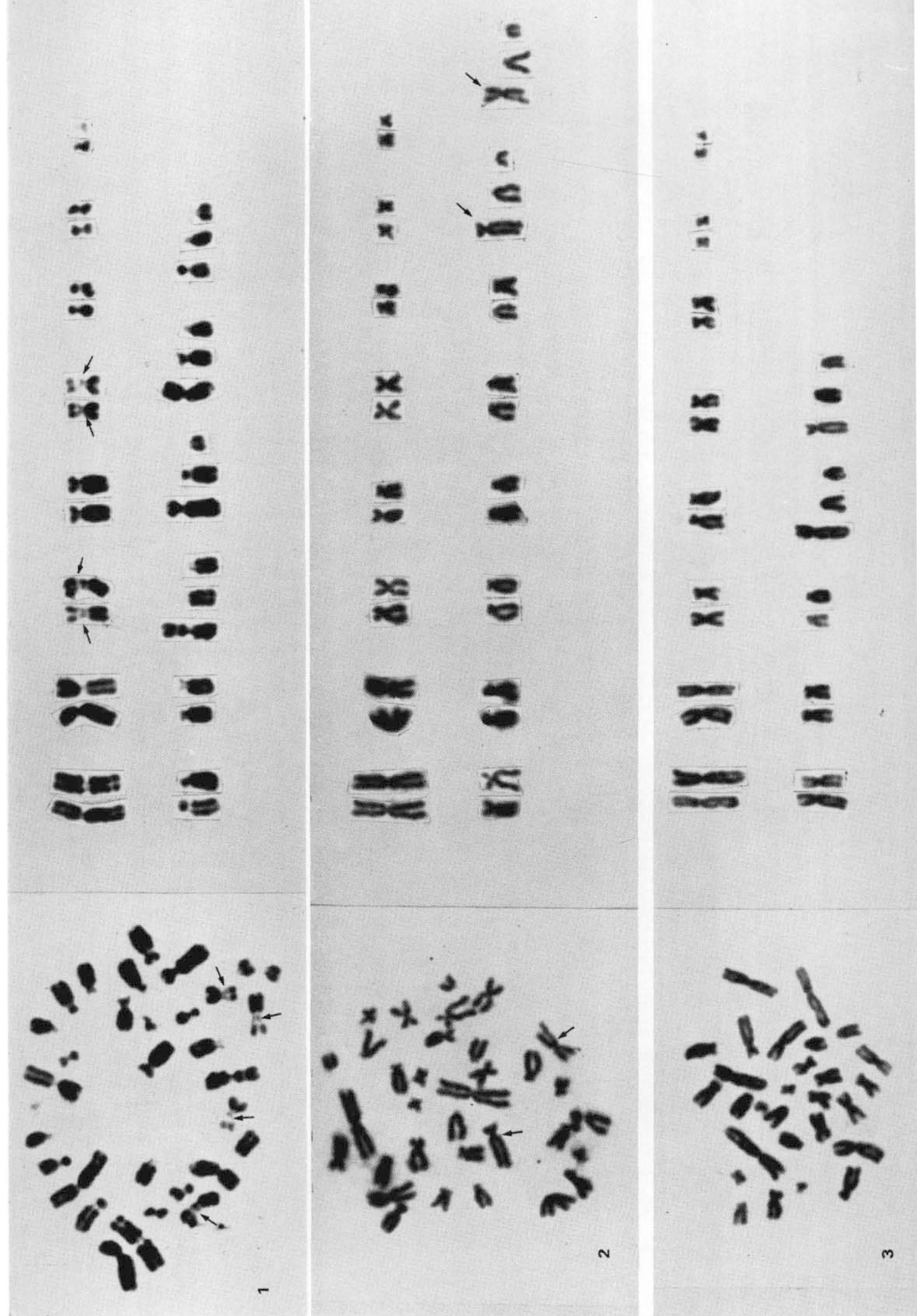




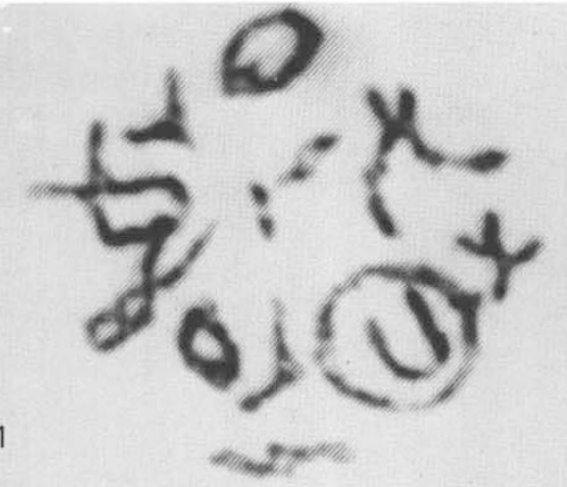

2

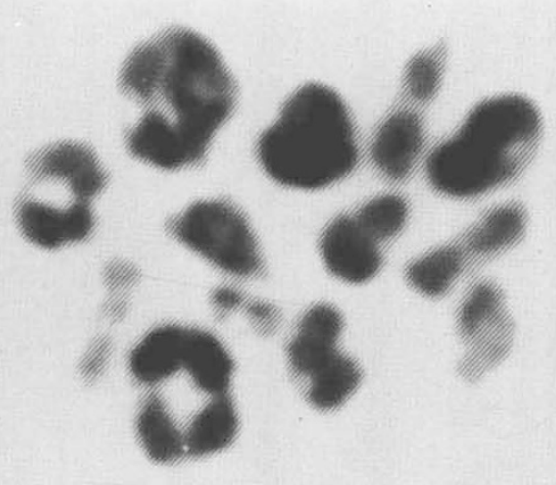

3

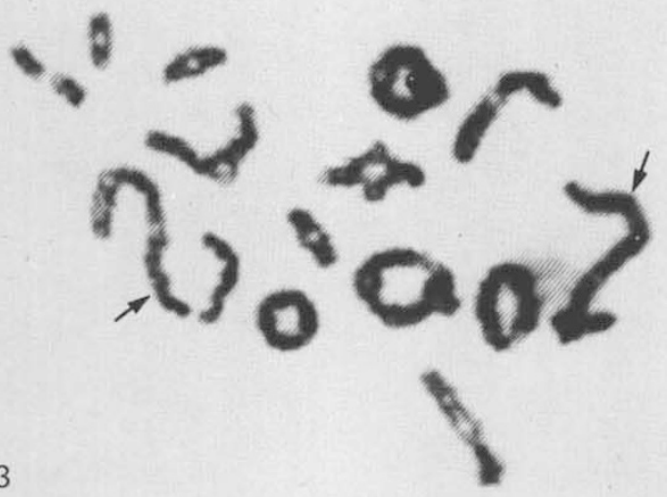

4
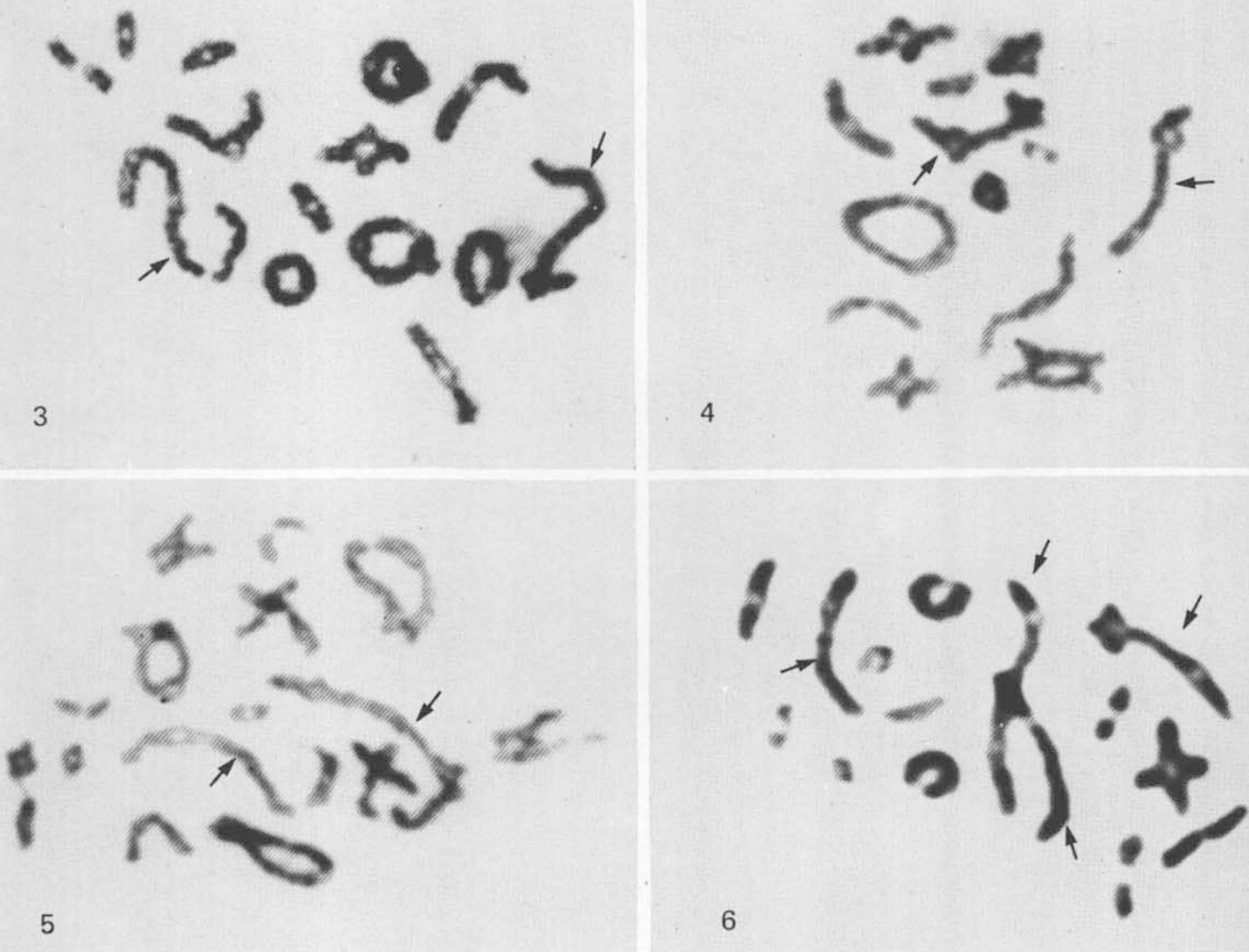

Plate III

Spermatocytes in meiosis. Heat-dried films, Giemsa.

1. Diplotene in the $2 n=26$ form. Three of the four large bivalents possess interstitial chiasmata.

2. Diakinesis in the $2 n=26$ form.

3-6. Diplotene (3-5) and early diakinesis (6) in individuals with intermediate chromosome numbers. Trivalents (arrowed) are seen in each cell. 
spread but erratic occurrence in marine gastropods. In any event it is unlikely to be either a cause or consequence of chromosome polymorphism in Nucella.

\section{(ii) Ecological findings}

\section{(a) The large-scale survey}

The overall distribution of the polymorphism in southern Britain is given in fig. 1. Three features of the pattern are apparent. Firstly, most of the populations are monomorphic $2 n=26$. Secondly, the polymorphism is restricted to a southern and western distribution but does not invariably occur in the south-west of the study area. Thirdly, where the polymorphism does occur there is a slight indication that it is more likely to be found in samples taken from populations in the major bays in the south-west (Mount's Bay, Plymouth Bay, Lyme Bay and Weymouth Bay) than in those from the chief headlands (Land's End, Start Point, and the Bill of Portland). Acrocentrics reach particularly high frequencies in Weymouth Bay (Detailed survey area A) and one sample in this area (from Lulworth Cove) is monomorphic $2 n=36$. There is no sign that the frequency of acrocentrics is associated with sample size.

Overall chromosome frequency is not associated with exposure. All the samples from both sides of the Bristol Channel are $2 n=26$ in spite of great differences in the degree of wave action; many of these samples originate from shores which are more sheltered than some in the Weymouth Bay area where the polymorphism is found.

The results of this survey will be considered further in the light of the findings of the two detailed surveys.

\section{(b) Detailed survey $A$ (the Dorset coast)}

This coastline was chosen for a detailed investigation since the general survey had shown not only that the frequency of acrocentrics was high in this area, but also that some populations were monomorphic for the low chromosome number. It thus seemed likely that it would be less difficult to infer what might be relevant environmental agents than elsewhere in southern Britain. Attempts to use Ballantine's exposure scale were unsuccessful for two reasons. (i) The indicator barnacle species Chthalamus stellatus and Balanus balanoides are rare; this scarcity may be related to the fact that most of the Dorset coast is Cretaceous chalk which may be too soft for the successful attachment of larvae (Lewis, 1964). Many of the relevant algae are missing also, possibly for similar reasons. (ii) Some of the relevant gastropods (e.g. Monodonta lineata) are rare or missing altogether and this does not relate in any obvious way to exposure.

In view of these difficulties the shores were subdivided as for the general survey. Exposed shores are the Bill of Portland, St Alban's Head, Durlston Head and The Foreland (fig. 2). Sheltered shores are Lulworth Cove, Kimmeridge creek and Chapman's Pool. The remainder have been classed as intermediate.

The results are shown in figs. 2 and 3. The former shows that acrocentrics are at a high frequency in all samples from Weymouth Bay and that this pattern is maintained eastwards as far as Swanage in spite of the fact that two of the samples were taken from exposed headlands. However, 


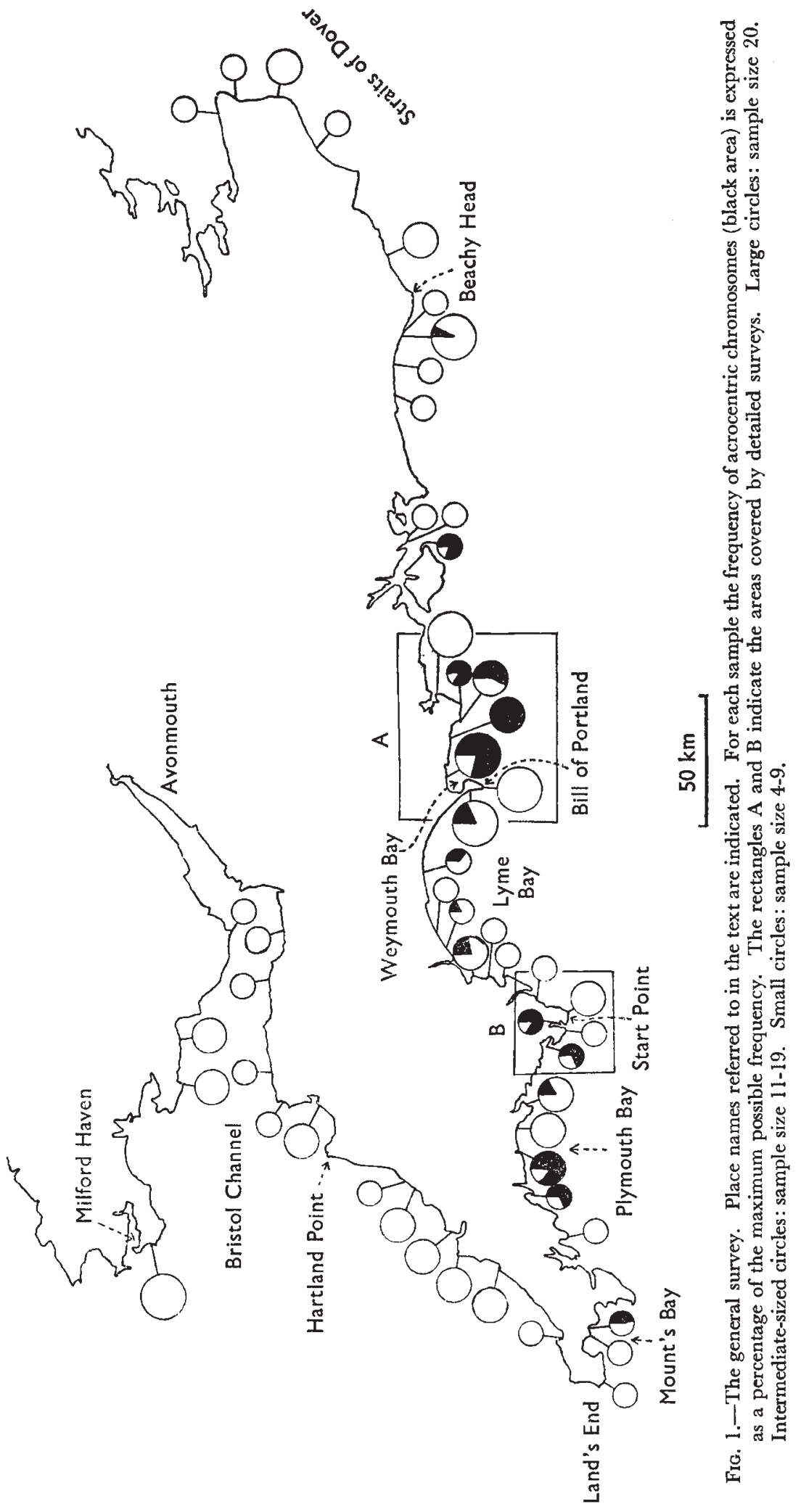




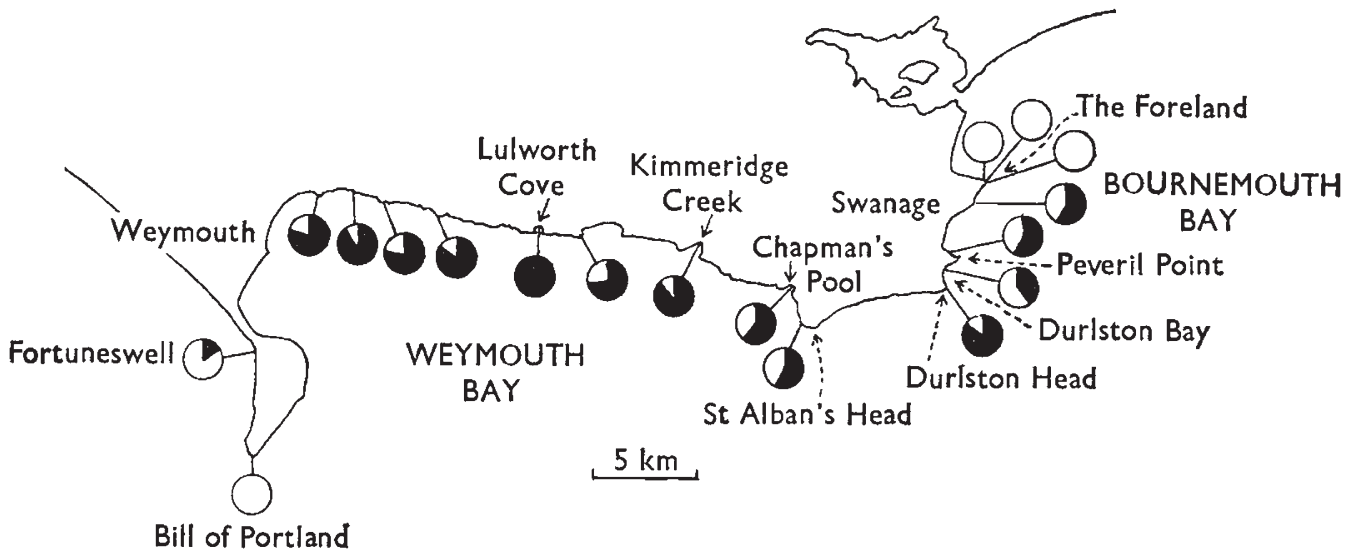

Frg. 2.-The Dorset Coast. Symbols as in fig. 1.

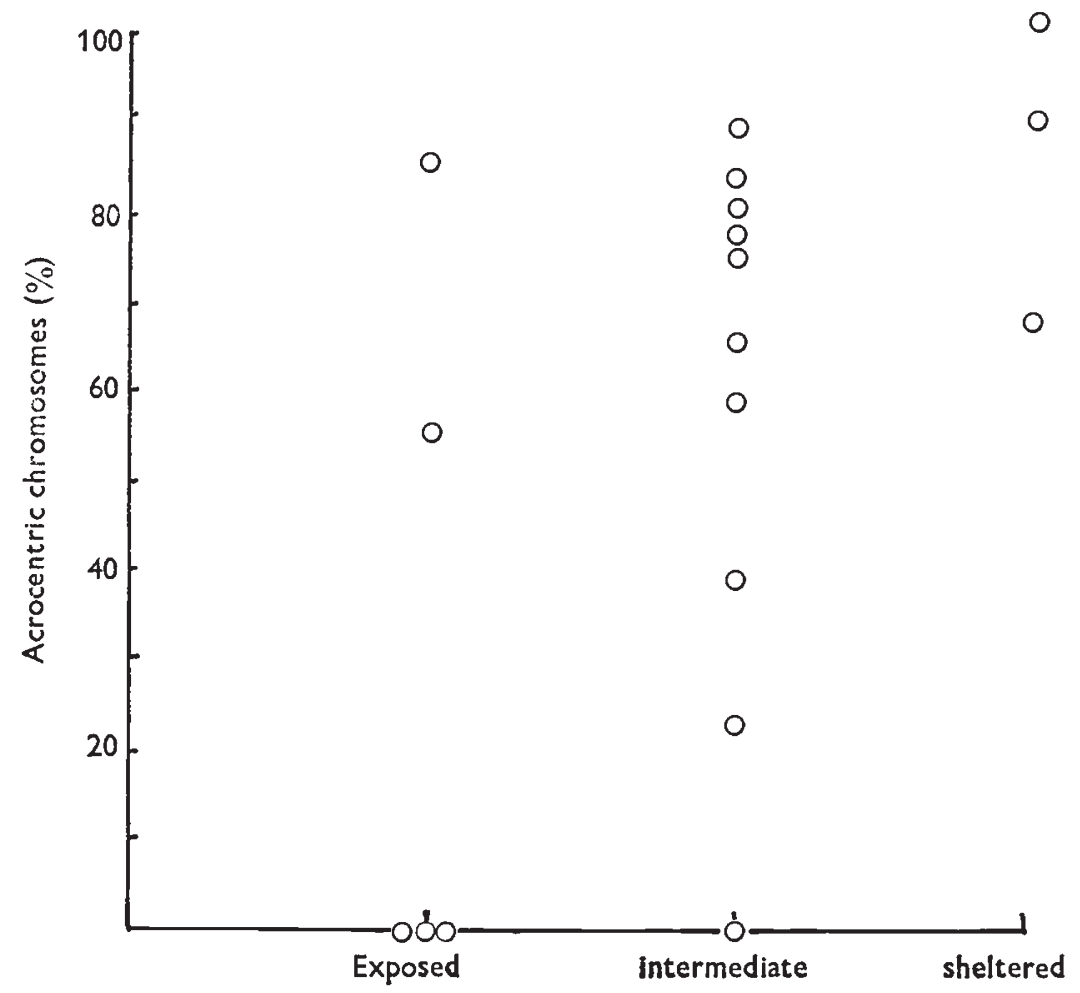

FIG. 3.-The Dorset Coast. Association between the frequency of acrocentric chromosomes and exposure.

fig. 3 shows that in the area as a whole the frequency of acrocentrics is lower in samples from exposed sites; Spearman's Rank correlation coefficient $r_{s}=+0.5530(\mathrm{P}<0.05)$.

Although the correspondence with exposure in this area is in the same direction as that found by Staiger at Roscoff, it is not clear why the frequency 
of acrocentrics should be generally so high along the Dorset coast, nor why the polymorphism should be absent over so much of the area covered by the general survey, and it is worth while considering what might be other factors responsible for these gross differences. Apart from variation in wave force, there are two other aspects of water movement which could be relevant, namely tidal range and tidal currents.

There is considerable variation in tidal range between areas and it is interesting that the coast between the Isle of Wight and the Bill of Portland has the narrowest tidal range in the whole of southern Britain: $1.5 \mathrm{~m}$ compared with $9 \mathrm{~m}$ in the Bristol Channel and $5 \mathrm{~m}$ in the Straits of Dover (Lewis, 1964). A small tidal range implies that vertical movement is slight; this is independent of variation in exposure.

Tidal currents are independent of both tidal range and wave action, though it is likely that a major headland (such as the Bill of Portland) experiences both strong currents and considerable wave force. The only information available for tidal currents is that in Tidal Stream Atlases in which the data are presented as sets of figures indicating the mean neap and spring rates at a particular position in the sea. The nearest recorders are usually about $0.15 \mathrm{~km}$ from the coast, and figures are available for 13 1-hour intervals of a complete tidal movement. Detailed observations are available for the western end of Weymouth Bay (Approaches to Portland Naval publication No. 257), and it is clear that tidal currents in this part of the bay are very weak; the mean of the mean neap rates is 0.1 knot off Weymouth compared with 1.9 knots off the Bill of Portland. At Fortuneswell (fig. 2) the current is again slight $(0.5 \mathrm{knot})$ but stronger than in Weymouth Bay. Further east the situation is more problematic since detailed figures are not available. Repeated visits have been made to the Swanage area (by C. R. B.) in order to assess what seem to be the main patterns of tidal currents. At ebb tide off the Foreland there is a strong current from NW to SE running past the headland, and the Coastguard at Swanage has informed us that it is sometimes impossible to stand in this current in only 18 inches of water at the Foreland. There appear to be no visible currents in Swanage Bay at any time, but a strong largely offshore current at Peveril Point runs against a relatively static body of water in Durlston Bay. There are no detectable currents round Durlston and St Alban's headlands.

It is possible that the chromosome polymorphism in Nucella responds to aspects of water movement other than wave action alone. Monomorphism for $2 n=26$ at Portland Bill and the Foreland is consistent with an association with either strong current or wave action or both, but the high frequency of acrocentrics at both Durlston and St Alban's headlands and everywhere else in Weymouth Bay, suggests that the weak tidal currents and narrow tidal range in the area as a whole may act selectively against a low chromosome number. It is interesting that Lulworth Cove, which is sheltered, has a narrow tidal range and presumably very weak currents, supports the only monomorphic $2 n=36$ population that has been found in southern Britain.

\section{(c) Detailed survey $B$ (south Devon)}

This survey was carried out in order to determine whether any effect of tidal currents on the polymorphism could be separated from any due to 
wave action. Apart from the fact that $\mathcal{N u c e l l a}$ is polymorphic in this area (fig. 1), south Devon was chosen for three reasons. Firstly, the littoral flora and fauna are sufficiently diverse for Ballantine's exposure scale to be used satisfactorily. Secondly, the area contains sites with differing exposure values ranging from exposed headlands to sheltered inlets (Ballantine's scale, values 2-6). Finally, the area contains an extensively branched tidal inlet (Kingsbridge estuary, though, since it is non-estuarine, it should more properly be called a creek). Both wave action and currents are reduced at the inner ends of the creek which has only a narrow outlet so that there is a strong tidal current at its narrowest point (Salcombe harbour) which is sheltered in terms of wave action. The creek opens into a bay which

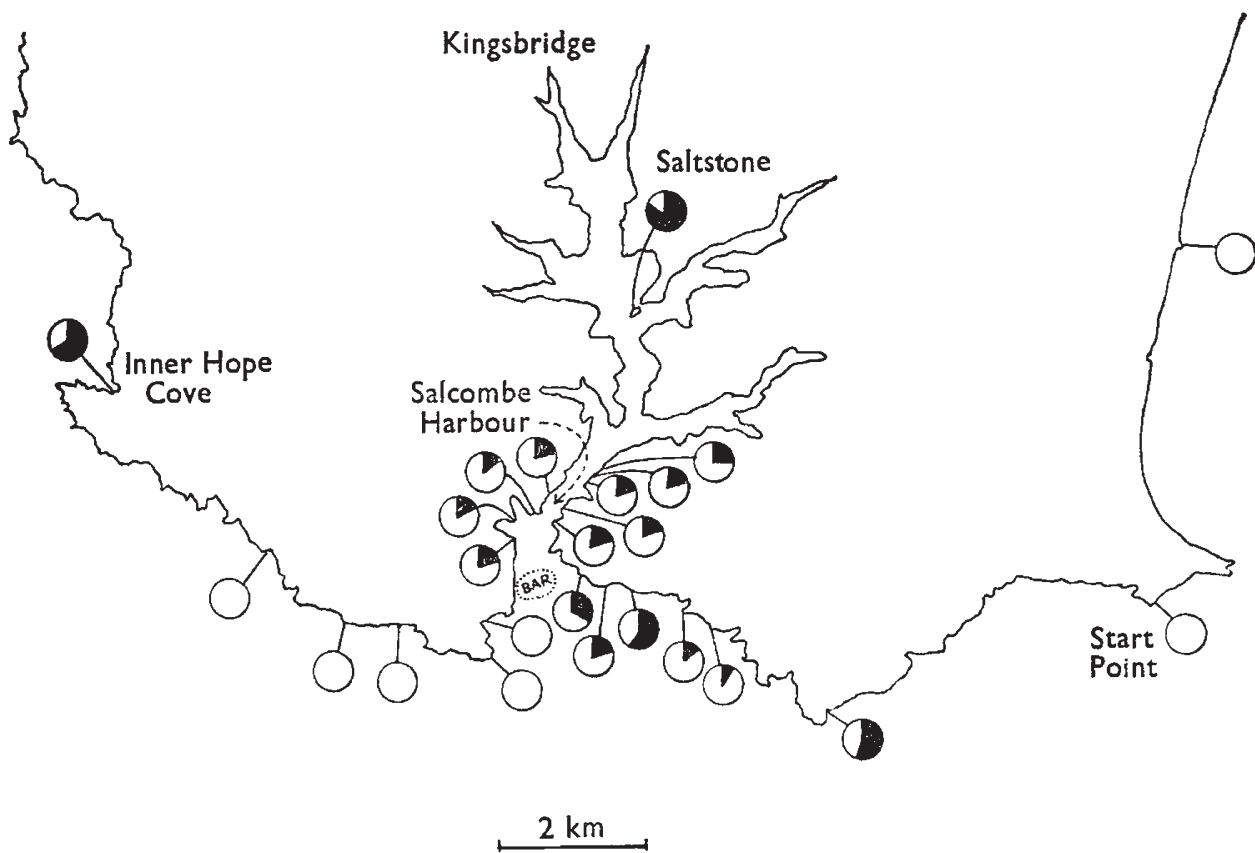

Frg. 4.-South Devon. Symbols as in fig. 1.

though more exposed than the creek is not subjected to any bottle-necking effect in tidal current. A narrow strip of submerged silt, known locally as the Bar (fig. 4) lies across the mouth of the creek and marks the point at which currents in the creek meet the body of water in the bay. It follows that 4 types of situation can be recognised: (i) sheltered with only weak currents (at the inner ends of the creek); (ii) sheltered with stronger currents (at the narrowest part of the creek); (iii) exposed with weak currents (in the bay into which the creek opens); (iv) exposed with strong currents (the headlands)

In order to minimise any effect of local irregularities in topography on water movement all the sampleswere taken at LWM from small promontories or outcrops (rather than from gulleys or crevices). The results are given in figs. 4 and 5 .

Fig. 5 shows that there is a clear association between the mean frequency 
of acrocentrics and exposure; $r_{s}=+0.4639(\mathrm{P}<0.05)$. The association is not an artifact of gross variation with geographical position alone since both Inner Hope Cove and the Saltstone (fig. 4) have high frequencies and are sheltered, but are separated by exposed sites where Nucella is monomorphic $n=13$. However, it can be seen from fig. 4 that the nine samples taken from the two sides of the creek at Salcombe harbour have consistently lower frequencies of acrocentrics than the three samples taken immediately outside the creek to the east where it is more exposed but where tidal currents are

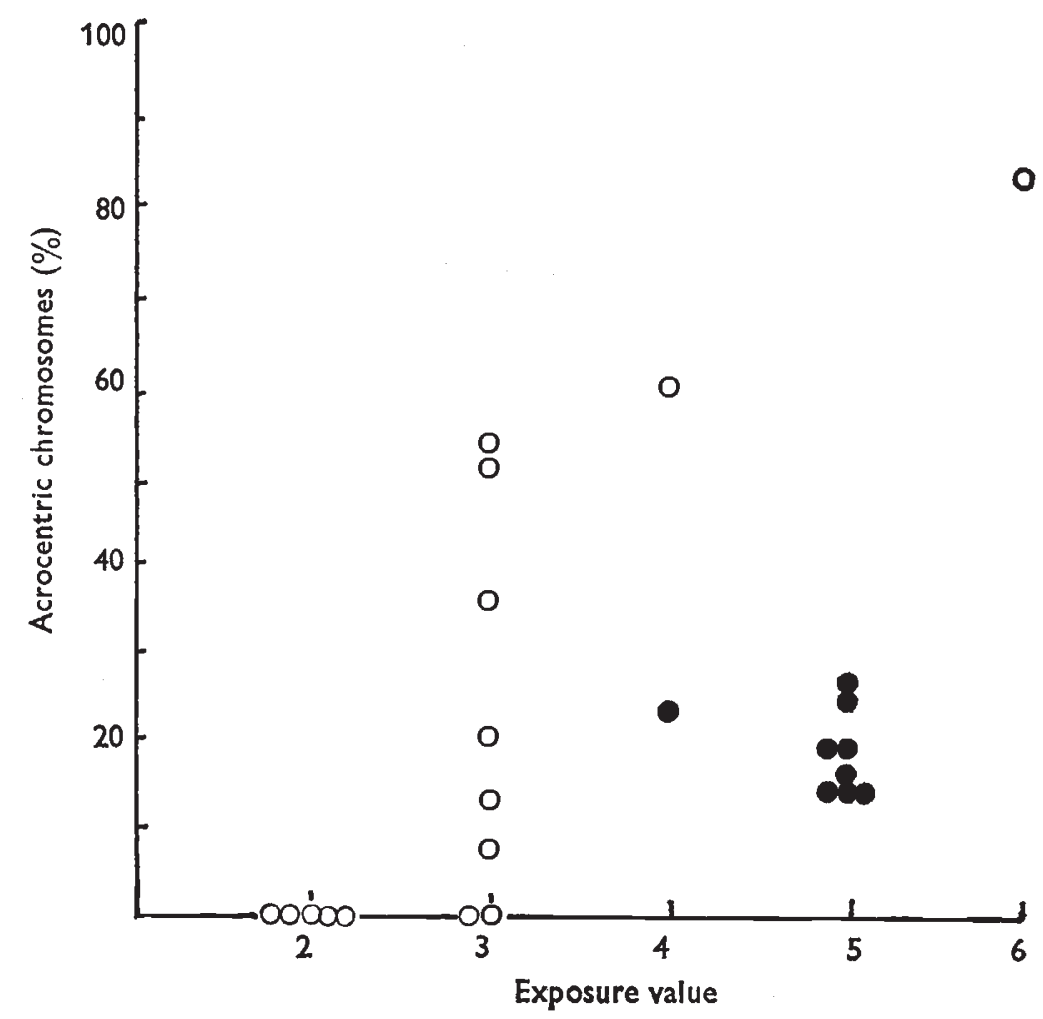

FIG. 5.-South Devon. Association between the frequency of acrocentric chromosomes and exposure. The grades of exposure are those defined by Ballantine (1961). $\quad=$ samples from Salcombe harbour. $O=$ remaining samples.

likely to be less strong. The difference is significant; Mann-Witney $U=1$ $(P=0.02)$, and is in the opposite direction that a simple association with wave action alone would have led one to expect, but is consistent with the suggestion that a low frequency of acrocentrics is associated additionally with strong tidal currents or other water movement. The corresponding downwards displacement of all the Salcombe harbour samples is apparent in fig. 5; if these samples are omitted, then the overall association with exposure becomes much more significant; $r_{s}=+0.8038(\mathrm{P}<0.001)$.

Since the two detailed surveys suggest that in areas where the polymorphism occurs at all a low chromosome number might be favoured under 
conditions where total water movement is greater, it is worth reconsidering the results of the general survey to determine whether they can be accommodated by this hypothesis. There are two problems. Why should the polymorphism be largely confined to south-facing bays in the south-west peninsula? And why should the monomorphism elsewhere always be $n=13$ and not $n=18$ ? The Tidal Atlas for the English and Bristol Channels (Naval Publication No. 250) shows that tidal currents are particularly strong in the Bristol Channel (means of the mean neap rates are 1.0, 1.09, 0.87 knots off Avonmouth, Hartland Point and Land's End respectively), strong round all the major headlands in the south-west and elsewhere in the English Channel (means of the mean neap rates are 0.79 and 0.8 knots off Beachy Head and Dover respectively), and weakest in the three major bays in the south (means of mean neap rates are $0.3,0.31$, and 0.2 knot in Mount's Bay, Plymouth Bay and Lyme Bay respectively). Overall water movement is greatest in the Bristol Channel (strong currents and large tidal range) and probably least in Weymouth Bay.

Although these data reflect in only an approximate manner the conditions on the shore itself, the apparent absence of the polymorphism from the Bristol Channel and from the eastern end of the English Channel, and the fact that Nucella is monomorphic $2 n=26$ where it is not polymorphic are in agreement with the hypothesis outlined above. Both the two polymorphic samples originating from east of the Dorset coast were taken from broad shallow-sloping shores (Bembridge in the Isle of Wight, and Cuckmere Haven in Sussex); both shores are rather exposed but are the only sampling sites in the east with a very gradual slope where tidal currents may perhaps be expected to be slight. It would be of interest to examine localities in the Bristol Channel where both wave action is reduced and currents are slight (e.g. Padstow Bay in Cornwall, and some parts of the Milford Haven, Pembroke); Nucella could be expected to be polymorphic if total water movement is the only factor governing the overall distribution of acrocentric chromosomes.

\section{Discussion and conclusions}

The cytological data amply confirm Staiger's (1954) findings, and provide additional information on the mitotic morphology of the chromosomes. However, many of the chromosomes are rather similar in size (e.g. most of the acrocentrics in the B group) and the karyotypes must be regarded as provisional only, until banding techniques allow a more precise identification. It is clear that the existence of trivalents in some individuals confirms the Robertsonian nature of the polymorphism.

It is worth pointing out that there are two confusing statements in the literature relating to the cytology of Nucella. Staiger (1957) makes the observation that " One metacentric corresponds to a pair of acrocentrics", and Hoxmark (1970) states that " the karyotype of the $n=18$ form consists entirely of acrocentrics" (a similar statement is made by Lewis and John, 1963). The first statement implies that each metacentric in the B group corresponds to two homologous chromosomes, in which case these metacentrics are isochromosomes and trivalents would not be formed in meiosis. The second statement is not true; the incorrect impression given by Staiger and Hoxmark may be artifacts of translation. 
The Robertsonian nature of the polymorphism implies that the chromosomal rearrangements resulting in numerical change, whatever their cause or direction, merely produce different linkage states and presumably therefore different epistatic interactions, rather than qualitative genetic differences between the various forms. Since only terminal chiasmata occur in trivalents, it is clear that at least in heterozygous individuals large numbers of loci are tightly linked, and since each possible chromosome rearrangement must affect the relationships between large numbers of genes it seems unlikely that there will be any simple explanation of the polymorphism.

There are two major difficulties. The first is that as there are several ways of achieving both a particular intermediate chromosome number and a sample mean frequency of acrocentrics, real differences between polymorphic populations may be obscured since at present it is not possible to distinguish different heterozygous arrangements. It is hoped that chromosome banding techniques will resolve this difficulty.

Notwithstanding the great variety of chromosomal architecture that is possible in Nucella, the distributional data suggest that environmental selective agents are powerful enough to produce certain similarities between areas (e.g. Roscoff, Dorset, South Devon). Even though it is possible only to infer that environmental selection occurs, these similarities suggest that it might be possible to identify the selective agent (or agents) rather accurately. Although it would be difficult to obtain really precise and relevant field data on water movements, the hypothesis that wave action, tidal currents or tidal range, or any combination of these act selectively is experimentally testable and predictive in nature, and it would certainly be premature to invoke historical explanations to account for large-scale distributional patterns.

The second difficulty is that there is no unequivocal information on what aspect of the animal's phenotype is affected by chromosome number. Staiger (1954, 1957) showed that at Roscoff shell thickness (minimum mean length and maximum mean weight) was greater in polymorphic colonies than in those monomorphic for either chromosome number. Since the polymorphic populations occurred in sites intermediate in exposure, it followed that shell thickness decreased as the exposure both increased and decreased, and that morphometric changes were associated with changes in chromosome number. However, Hoxmark (1971) found that there were no differences in the shell weight/body weight ratio between a $2 n=36$ sample from Roscoff and a $2 n=26$ one from Norway, but that this ratio differed between two monomorphic $2 n=26$ populations. Hoxmark examined only four populations and clearly more data are required.

Crothers (1973) has shown that in Pembrokeshire blunt shells with a large aperture predominate at exposed site and that conversely long shells with a small aperture are frequent on sheltered shores. Kitching et al. (1966) have shown experimentally that this variation is adaptive since individuals with a large aperture have greater power of adhesion than those with a smaller aperture, relative to total shell length. Nucella had not been investigated cytologically in Pembrokeshire, and shell variation has not been studied throughout the area described in this paper; it will be necessary to bring these lines of enquiry together to determine whether there is any overall association between chromosome number and shell morphology. 
Acknowledgements.-We should like to thank all those who assisted with the collecting, in particular Dr H. M. Bantock, Dr M. Carter, Mr J. H. Crothers, Mrs O. J. Etherington, Mr M. Guiry, Dr and Mrs P. H. Harvey, and Mr and Mrs T. Rix.

\section{REFERENGES}

Ballantine, w. J. 1961. A biologically-defined exposure scale for the comparative description of rocky shores. Field Studies, 1 (3), 1-19.

BANTOCK, c. R. 1970. Experiments on chromosome elimination in the gall midge Mayetiola destructor. 7. Embryol. Exptl. Morph., 24, 257-286.

BANTOCK, C. R. 1972. Localisation of chiasmata in Cepaea nemoralis (L.) Heredity, 29, 213-221.

GROTHERS, J. H. 1973. On variation in Nucella lapillus (L): shell shape in populations from Pembrokeshire, South Wales. Proc. malac. Soc. Lond., 40, 319-327.

HOXMARK, R. c. 1970. The chromosome dimorphism of Nucella lapillus (Prosobranchia) in relation to wave exposure. Nytt magasin for zoologi, 18, 229-238.

HOXMARK, R. c. 1971. Shell variation of Nucella lapillus in relation to environmental and genetical factors. Norwegian Journal of Zoology, 19, 145-148.

HsU, T. c. 1973. Longitudinal differentiation of chromosomes. Ann. Rev. Gen., 7, 153-175.

xitching, J. A., MUNTZ, L., AND Ebling, F. J. 1966. The ecology of Lough Ine XV. The ecological significance of shell and body form in Nucella. F. An. Ecol., 35, 113-126.

LEWIS, J. R. 1964. The Ecology of Rocky Shores. English Univ. Press.

LEWIS, K. R., AND John, B. 1963. Chromosome Marker. J. A. Churchill, London.

MAYR, E. 1963. Animal Species and Evolution. Harvard Univ. Press.

MEREDITH, R. 1969. A simple method for preparing meiotic chromosomes from mammalian testis. Chromosoma, 26, 254-258.

patron, J. L. 1969. Chromosome evolution in the pocket mouse Perognathus goldmani (Osgood). Evolution, 23, 645-662.

StAIGER, H. 1954. Der chromosomendimorphism beim Prosbranchier Purpura lapillus in Beziehung zur Okologie der Art. Chromosoma, 6, 419-478.

STAIGER, H. 1957. Genetical and morphological variation in Purpura lapillus with respect to local and regional differentiation of population groups. Annee Biologigue, 33, 251-258. 